\title{
Definição de transporte: uma reflexão sobre a natureza do fenômeno e objeto da pesquisa e ensino em transportes
}

\author{
Marcos Thadeu Queiroz Magalhães¹, Joaquim José Guilherme de Aragão², Yaeko Yamashita³
}

\begin{abstract}
Resumo: O que é o transporte? Quais seus caracteres distintivos? O que é um sistema e, mais especificamente, um sistema de transportes? É possível formalizar definições sobre esses aspectos? Com vistas a tornar mais claro o objeto do da pesquisa e ensino em transportes, o presente artigo parte dessas questões como elementos motivadores, na tentativa de prover novos elementos para essa reflexão. E, nesse sentido, traz para a discussão sobre transporte teorias ainda pouco exploradas, mas de grande fecundidade, para a busca de um arcabouço teórico robusto e definições mais claras. Nesse âmbito, apresenta-se a teoria de sistemas de Mario Bunge, e desenvolve-se reflexões sobre a noção de transporte, sistemas, sistemas de transporte, seus caracteres distintivos e implicações acerca dos métodos para a devida abordagem desses fenômenos.
\end{abstract}

Palavras-chave: Transportes. Sistema de Transporte. Definição. Teoria de Sistemas. Mario Bunge.

\begin{abstract}
What is this thing called Transport? What are its unique features? What is a system and, more precisely, a transport system? Is it possible to formalize a definition of such things? As to provide a clearer definition of Transport Research's object, this paper addresses those questions and brings new elements into discussion. To debate about Transport, we present promising theories yet to be explored, as a way to provide a more robust theoretic background and a clearer set of definitions. On this scope, we present Mario Bunge's System Theory and we discuss the notions of transport, transport system, its distinctive features and its implications on the adequate methods to address those phenomena.
\end{abstract}

Keywords: Transport. Transport Systems. Definition. Theory of Systems. Mario Bunge.

\section{INTRODUÇÃO}

Usualmente, utiliza-se o termo transporte para designar o deslocamento para o trabalho, escola, para atividades de lazer, compras, o deslocamento de encomendas e cargas diversas e outra gama de fenômenos semelhantes e de evidente importância na vida cotidiana. A preocupação de desenvolver meios para possibilitar esses deslocamentos existe desde a Antiguidade, quando os homens já tinham preocupação com as rotas comerciais, com a marcha dos exércitos, com o provimento de água e outros recursos naturais etc. (MUMFORD, 1998). Apesar disso, o desenvolvimento de um campo de estudos exclusivamente voltado para o transporte, com profissionais e estudiosos voltados para o tema, é bastante recente, tendo tido seu início no século XX.

À medida que esse campo (Transportes) de estudo avança, espera-se correspondente amadurecimento e crescente nível de formaliza-

\footnotetext{
1 Universidade Federal da Bahia (marcos.thadeu@ufba.br).

2 Universidade de Brasília (aragao@unb.br).

3 Universidade de Brasília (yaeko@unb.br).
}

Manuscrito recebido em 31/01/2013 e aprovado para publicação em 03/06/2014. Este artigo é parte de TRANSPORTES v. 22, n. 2, 2014. ISSN: 2237-1346 (online).

DOI: http://dx.doi.org/10.14295/transportes.v22i3.655. ção. Diante disso, as definições pouco precisas providas pelo senso comum não se fazem mais suficientes. De início, algumas questões surgem, a exemplo do que é transporte e qual sua distinção em relação a outros deslocamentos (como em “o que diferencia a viagem de uma pessoa para seu trabalho e um pedaço de madeira carregado pela força das águas de um rio?”). Se não abordadas a contento, questionamentos sobre a relevância e legitimidade do campo de estudos poderiam surgir, fundadas em visões providas por outras ciências e linhas de investigação. $\mathrm{O}$ que aqui se entende é que o campo pode evitar os riscos de reducionismos a ciências mais maduras (ou seja, evitar o "economicismo", "psicologismo”, “fisicalismo”, "sociologismo”, etc). Em outras palavras, apesar de fazer uso de teorias de diversas origens, há incomensurabilidade no fenômeno Transporte em relação às abordagens das demais ciências.

Assim, faz-se fundamental definir transporte e distingui-lo, enquanto fenômeno, dos demais eventos e fatos que formam a realidade vivida pelo homem. Este trabalho aborda alguns desses aspectos. Nesse sentido, o presente artigo está estruturado como segue. Primeiramente, é apresentado o principal arcabouço filosóficoteórico para abordagem do tema transporte e sis- 
temas de transporte. Em seguida, explora-se o termo 'transporte' e a natureza do fenômeno e da noção de sistema de transporte. Por fim, tecese comentários gerais sobre o trabalho e apresenta-se indicativos para futuras investigações. Espera-se, desta forma, reavivar as discussões sobre o objeto da pesquisa e ensino em transportes, com vistas ao surgimento e desenvolvimento de novas pesquisas, métodos e tecnologias para abordagem deste fenômeno tão importante socialmente.

\section{BUNGE E A VISÃO DE SISTEMA}

Na pesquisa em Transporte, uma noção que, historicamente, tem tido uma função estrutural é a de sistema. Diversas definições foram apresentadas por diferentes autores, principalmente no que concerne a composição do sistema de transporte (MORLOK, 1978; HAY, 1977; SUSSMAN, 2001; PAPACOSTAS \&PREVEDOUROS, 1993) e, para um panorama geral, bem como uma análise detalhada de cada uma, pode-se consultar o trabalho de Magalhães (2010, p.119-129). No momento, limitar-se-á a abordar apenas a noção, e respectiva definição, de sistema. Sobre isso, Bunge (1979, p.16) comenta a existência de diversos trabalhos sobre o assunto, mas que todos eles podem ser redutíveis a uma de três definições mais gerais, que se tornaram bastante populares, mas, ao seu ver, inadequadas, a saber: (i) a primeira, entende sistema como "um conjunto de elementos inter-relacionados"; (ii) a segunda, define sistema como uma "caixa-preta" com inputs (entradas) e outputs (saídas); e, (iii) a terceira que afirma que sistemas são relações binárias.

Para compreender a razão pela qual Bunge julga inadequadas as definições correntes, é necessário fazer referência ao seu modelo ontológico e sua teoria específica de sistemas. Inicialmente, ele apresenta a distinção entre agregado e sistema. Para Bunge (1979, p.4), agregado é

(...) uma coleção de itens sem qualquer vinculo entre eles, e portanto, sem integridade e unidade. Agregados podem ser tanto conceituais quanto concretos (materiais). Um agregado conceitual é um conjunto (mas nem todo conjunto é um agregado conceitual: um conjunto dotado de uma estrutura é um sistema conceitual). Um agregado concreto ou material, por outro lado, é uma coisa composta, cujos componentes não estão acoplados, ligados, conectados ou vinculados, tal qual um campo constituído por dois outros campos superpostos (...)

e sistema é

(...) um objeto complexo, cujos componentes são inter-relacionados. Se os componentes são conceituais, assim também é o sistema; se são concretos ou materiais, então eles constituem um sistema concreto ou material. Uma teoria é um sistema conceitual, uma escola é um sistema concreto do tipo social.

Retomando as definições de sistemas apresentadas inicialmente, à luz da concepção de Bunge, fica mais fácil entender por quais razões ele as julga inadequadas. A primeira, que define sistema como um conjunto de elemento inter-relacionados, se limita apenas a sistemas conceituais, uma vez que conjunto é uma noção abstrata e imaterial. A segunda definição é interessante desde que a estrutura interna do sistema não seja relevante (BUNGE, 1979, p.16). Na terceira acepção, sistema é apenas um objeto conceitual (relações binárias).

\subsection{Conceito e definição geral de sistema}

Em discurso não-formalizado, Bunge (1979, p.4) afirma que qualquer sistema tem composição definida, ambiente definido e estrutura definida. A composição do sistema é o conjunto de seus componentes; o ambiente, 0 conjunto de itens com os quais ele está conectado; e a estrutura, as relações entre seus componentes, bem como entre estes e os elementos do ambiente.

A primeira formalização do conceito de sistema conforme proposto por Bunge (1979, p.5) é como segue. Seja $T$ um conjunto não-vazio. Então, o terno ordenado $\sigma=\langle\mathscr{C}, \mathscr{E}, \mathscr{Q}\rangle$ é (ou representa) um sistema sobre $T$, se $\mathscr{C}$ e são subconjuntos mutuamente excludentes de $T$ (ex. $\mathscr{C} \cap \mathscr{E}=\varnothing$ ), e $\mathscr{\wp}$ é um conjunto não-vazio de relações na união de $\mathscr{C}$ e $\mathscr{E}$. O sistema é conceitual se $T$ é um conjunto de itens conceituais, e concreto (ou material) se $T \subseteq \Theta$ é um conjunto de entidades concretas, por exemplo coisas (para a definição precisa de coisa, ver Bunge, 1977, 
cap. 1 a 3).

Entretanto, segundo o autor, para se obter a definição adequada, as noções de composição

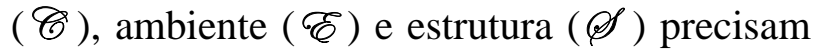
ser formalizadas. Essas formalizações, conforme propostas por Bunge, são apresentadas a seguir, especificamente para os sistemas concretos.

\subsection{Definição de sistema concreto por Bunge}

Para compreender a definição de sistema dada por Bunge, é necessário ter as definições de A-composição, A-ambiente e A-estrutura esclarecendo que o 'A' corresponde ao vocábulo 'atômico'. Neste texto, as notações serão as mesmas utilizadas no texto original de Bunge. Conforme entende o autor, a composição de um sistema não é apenas uma coleção de suas partes, mas o conjunto de seus "átomos". E define, simbolicamente, a composição absoluta e a Acomposição da seguinte forma (BUNGE, 1979, p.5-6):

Seja $A \subseteq \Theta$ uma classe de coisas e $x$ uma coisa qualquer (ex. $x \in \Theta$ ). A composição (absoluta) de $x$ é o conjunto de suas partes:

onde:

$$
\widetilde{(}(x)=\{y \in \Theta \mid y \sqsubset x\}
$$

$\mathscr{C}(x)$ : Composição absoluta de $x$

' $y \sqsubset x$ ' designa “ $y$ é parte de $x$ ”

E a A-composição de $x$ é o conjunto de suas A-partes (coisas do tipo 'A'):

$$
\sigma_{A}(x)=\mathscr{C}(x) \cap A=\{y \in \mathrm{A} \mid y \sqsubset x\}
$$

onde:

$$
\begin{aligned}
& \widetilde{\overparen{A}}_{A}(x) \text { : A-composição de } x \\
& 8(x)
\end{aligned}
$$

Necessário à compreensão de seu modelo, Bunge (1979, p.6) introduz o conceito de ligação, conexão ou acoplamento entre componentes de uma coisa. Para ele, esse conceito - de conexão - é distinto de relações como "ser mais velho”, “estar ao lado” etc. Duas coisas estão conectadas quando pelo menos uma delas age sobre a outra. E, se uma coisa age sobre outra, ela modifica a linha de comportamento, trajetória ou história da última. A relação de ação é simbolizada da seguinte forma: se uma coisa $a$ age sobre uma coisa $b$ escreve-se que ' $a \triangleright b$ '.

A noção de A-ambiente de uma coisa $x$ com uma A-composição $\mathscr{\mathscr { C }}_{\hat{A}}(x)$ é definida como o conjunto de todas as coisas, que não estão contidas em $\mathscr{\mathscr { C }}_{A}(x)$, que agem sobre, ou recebem a ação de $\mathscr{C}_{A}(x)$. Na linguagem formal adotada por Bunge, escreve-se:

$$
\begin{gathered}
\mathscr{E}_{A}(x)=\{y \in \Theta \mid \neg(y \in \\
\left.\left.\mathscr{\sigma}_{A}(x)\right) \&(\exists z)(z \sqsubset x \&(y \triangleright z \vee z \triangleright y))\right\}
\end{gathered}
$$

onde

$$
\begin{aligned}
& \mathscr{E}_{A}(x) \text { : A-Ambiente de } x \\
& \mathscr{C}_{A}(x) \text { : A-Composição de } x
\end{aligned}
$$

Por fim, a estrutura é o conjunto de todas as relações entre os componentes de uma coisa, bem como as relações entre estas e as coisas no ambiente. A formalização da definição de estrutura, para um sistema concreto, é apresentada no próximo item.

\subsection{Formalização das características de sistema concreto por Bunge}

Um objeto é um sistema concreto se, e somente se, for composto por pelo menos duas coisas diferentes e conectadas (BUNGE, 1979, p.6).

As três características de um sistema, cujas noções foram adiantadas no subitem anterior, são (BUNGE, 1979, p.7): A-Composição, AAmbiente e A-Estrutura.

Seja $\sigma \in \Sigma$ um sistema concreto e $A \subset \Theta$ uma classe de coisas. A A-composição de $\sigma$ no tempo $t$ é o conjunto de todas as suas A-partes em $t$. Na linguagem formal de Bunge escreve-se:

$$
\widetilde{\sigma}_{A}(\sigma, t)=\{x \in \mathrm{A} \mid x \sqsubset \sigma\}
$$

$\mathrm{O}$ A-ambiente de $\sigma$ no tempo $t$ é o conjunto de todas as coisas do tipo $A$, que não são componentes de $x$, mas que agem ou sofrem a ação de componentes de $\sigma$ no tempo $t$. Em termos formais da linguagem utilizada por Bunge, escreve-se como segue:

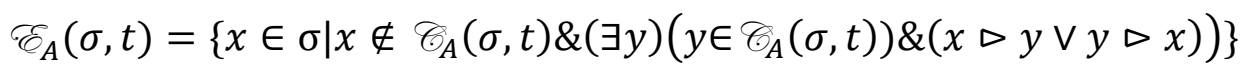


O A-estrutura de $\sigma$ no tempo $t$ é o conjunto de relações, em particular conexões, entre os componentes de $\sigma$, e entre estes e as coisas no A-ambiente de $\sigma$ no tempo $t$. Em termos formais da linguagem utilizada por Bunge, escrevese da seguinte forma:

$$
\begin{gathered}
\mathscr{A}_{A}(\sigma, t)=\left\{R_{i} \in\right. \\
\left.\mathbb{B}_{A}(\sigma, t) \cup \overline{\mathbb{B}}_{A}(\sigma, t) \mid \mathbb{B}_{A}(\sigma, t) \neq \emptyset \& 1 \leq i \leq n\right\}
\end{gathered}
$$

Onde:

$\mathbb{B}_{A}(\sigma, t)$ : conjunto de conexões

$\overline{\mathbb{B}}_{A}(\sigma, t)$ : conjunto de relações que não são de conexão

$R_{i:}$ uma relação qualquer

\subsection{Tecnossistema}

A noção de tecnossistema lança luz sobre um aspecto central desse tipo de sistema: o uso de artefatos e a produção (outputs) direcionada a membros de uma sociedade. Considerando a noção intuitiva de sistema de transporte, na qual a figura dos veículos surge de forma marcante à mente, a ideia de tecnossistema parece se aproximar dessa noção. Para tornar mais clara a ideia desse tipo de sistema, é oportuno referenciar a definição oferecida por Bunge (1979, p.202).

Um sistema $\tau$ é um tecnossistema se, e somente se,

(i) a composição de $\tau$ inclui seres racionais e artefatos;

(ii) o ambiente de $\tau$ inclui componentes de uma sociedade;

(iii) a estrutura de $\tau$ inclui produção, manutenção ou uso de artefatos.

Pode-se dizer que um tecnossistema seja um subsistema de uma sociedade humana mas, obviamente, não o inverso. Todos esses elementos teóricos lançam novas perspectivas para a reflexão sobre transportes e sistemas de transportes, perspectivas essas que devem ser melhor exploradas com o avanço da pesquisa na área. A utilização dessa linha como metateoria para análise e comparação entre teorias sobre sistemas de transportes, por exemplo, foi explorada em Magalhães (2010).

\section{DEFININDO TRANSPORTE}

\subsection{Levantamento de aspectos ligados ao vocábulo}

O vocábulo transportar pode assumir as seguintes acepções, estas selecionadas em função da relevância para a discussão (HOUAISS et al., 2001):

- (transitivo direto, bitransitivo) levar ou conduzir (seres animados ou coisas) a (determinado lugar); carregar;

- (pronominal) passar-se ou mudar-se de um lugar para outro, transferir-se.

A partir disso, chama-se atenção para alguns aspectos do verbo transportar: primeiro, suas acepções aqui apresentadas referem-se a mudança de lugar; segundo, no processo, existe um objeto (seres animados ou coisas); e terceiro, pode assumir forma reflexiva, indicando que quem transporta pode ser também o que é transportado. Esses aspectos serão importantes para a discussão do conceito de transporte realizado mais adiante.

Ainda com relação ao vocábulo, cabe observar que ele pode assumir forma substantiva, transporte, designando, assim, uma classe específica de fenômenos.

\subsection{Levantamento de definições em manuais especializados}

Os paradigmas sintetizam os principais elementos de uma área de estudos, contendo elementos ontológicos, teóricos, metodológicos (MAGALHÃES, 2010). Os paradigmas de um campo de estudos podem ser identificados nos manuais utilizados para a formação dos novos pesquisadores. Assim, a consulta a esses manuais pode oferecer uma definição mais especializada do termo transporte, enriquecendo, assim, a reflexão sobre a natureza do fenômeno.

Morlock (1978, p.5) traz duas acepções para a palavra "transporte" tiradas de dicionários de língua inglesa:

- an act, process, or instance of transporting or being transported; e,

- to transfer or convey from one place to another.

As duas acepções apresentadas assemelham-se aquelas apresentadas na seção anterior, incluindo a forma reflexiva (transportar e ser transportado) observada. Observe, entretanto, que a primeira definição apresentada por Morlock faz uma referência circular, não explicando o que é transportar. Esse tipo de definição é muito comum em dicionários e é aceito quando se trata de linguagens naturais. Entretanto, 
pouco tem a oferecer em contextos mais especializados. Sua importância, no máximo, reside em noções sintáticas sobre o vocábulo.

Ainda sobre Morlock (1978, p.5), ele traz a definição de engenharia de transportes como sendo

a aplicação de ciência e matemática pela qual as propriedades da matéria e das fontes de energia na natureza são utilizadas para movimentar passageiros e mercadorias de forma útil à humanidade.

Antes de discutir a definição dada por Morlock, cabe reproduzir a definição trazida por Papacostas e Prevedouros (1993, p.1) para sistema de transporte como sendo

as instalações fixas, as entidades de fluxo, e o sistema de controle que permite que pessoas e mercadorias vençam a fricção do espaço geográfico de forma eficiente, permitindo participar tempestivamente em alguma atividade desejada.

Por hora, o foco de reflexão está voltado para a definição de 'transporte' de forma que a discussão sobre o que seja 'engenharia' ou 'sistema de transporte' não será abordada nesta oportunidade. Feita esta ressalva, cabe identificar nessas definições, elementos úteis para explorar o conceito de Transporte.

Nas definições acima, um aspecto em especial é digno de atenção: a noção de que o transporte serve a um propósito, um desejo (expresso em "useful to mankind" $e$ "in order to participate in a timely manner in some desired activity"), ou seja, tem como uma de suas propriedades a intencionalidade. No entanto, essa propriedade não é enfatizada nas definições encontradas até aqui, o que pode levar a uma sobreposição entre transporte e outros tipos de deslocamentos, interpretação pouco interessante para o desenvolvimento da pesquisa sobre transporte e da própria identidade do campo de estudos.

\subsection{Transporte e ação intencional}

O Transporte é um processo humano intencional, algumas das definições (se é que o são) vistas anteriormente sugerem essa noção. Os fenômenos que percebemos no dia-a-dia como as pessoas se deslocando de um lado para outro, veículos automotores lotando ruas e uma infinidade de outros exemplos são apenas uma parte desse processo mais complexo, cuja totalidade não é observável se limitada a essa gama de "aparências". Para melhor compreender isso, tome-se a analogia feita por Andler et al (2005, p.567) para explicar a dificuldade de observação da ação intencional:

Imaginemos o caso de Pedro cruzando na rua com a diretora da escola primária que seus filhos frequentaram. Ele tinha, na época, brigado com ela e se pergunta se não deveria propor uma reconciliação. O que ele imagina, depois decide fazer, não é deslocar seu braço e sua mão, de modo que seu chapéu seja brevemente levantado, em cinco centímetros acima de sua cabeça; também não é dar, a um fotógrafo de emboscada, a oportunidade de ilustrar um artigo sobre os costumes antiquados de uma cidadezinha do interior;(...) o que Pedro faz, deliberadamente (...), é cumprimentar a diretora da escola que seus filhos frequentaram. $O$ agente escolhe fazer $X$, e realiza sua escolha fazendo $Y$ : o primeiro "fazer" tem sentido, aparentemente, diferente do segundo - no caso mais simples, $X$ é realizado pelo agente, ao passo que $Y$ só é realizado, de fato, por uma parte do corpo do agente.

Em relação ao Transporte vale a analogia. Os fenômenos observados e comumente chamados de Transporte são apenas parte da ação intencional. Esta envolve a escolha do sujeito (X), a qual é realizada fazendo-se, dentre outras coisas, o deslocamento de um objeto (Y), por exemplo: (1) o produtor de soja do Mato Grosso quer vender seu produto na Europa, ele realiza essa ação exportando o produto através de um porto no Maranhão; ou (2) um estudante deseja participar das atividades educacionais, ele realiza essa ação deslocando-se até a escola na qual está matriculado. Cabe observar que seria possível citar uma série de ações na categoria Y. Entretanto, o ponto destacado aqui é a percepção de que o processo de transporte envolve duas dimensões: uma explícita e observável que não é a determinante, mas apenas a manifestação de uma escolha; e, uma velada, a ação intencional, engajada, que é a determinante. Ou seja, a real 
razão pelo qual os deslocamentos que vemos ocorrem não é conhecida senão pelo próprio “Sujeito de Transporte”. Qualquer observador exterior pode apenas conjecturar sobre as razões, ou então questionar diretamente o agente.

Entender Transporte como ação intencional opera uma mudança profunda na pesquisa em transportes, exigindo revisão metodológica e a adoção de novas ferramentas e instrumentos hoje ainda pouco conhecidos e explorados dentro da área. Sobre essas alterações se falará mais adiante. Por ora, cabe fornecer elementos que mostrem que o caráter intencional está incorporado, intuitivamente e com limitações, dentro do método da pesquisa em transporte.

\subsubsection{Suporte para a interpretação do trans- porte enquanto fenômeno humano: uma leitura do método da pesquisa e prática tradicional em transporte}

A afirmação sobre a natureza humana do transporte não vem do vazio, mas sim de uma reflexão sobre o objeto de estudo, bem como dos trabalhos da comunidade científica que há muito trazem elementos cuja cuidadosa observação acaba por sustentar essa natureza. A intenção aqui não é esgotar toda e qualquer evidência sobre o assunto, mas apenas prover alguns desses elementos que auxiliam na corroboração do argumento posto na seção anterior.

No que diz respeito à intencionalidade, ao se falar sobre planejamento de transportes, sempre se fala sobre as "linhas de desejo", que nada mais são que a representação de desejos de deslocamentos (supostos ou declarados) dos habitantes de uma dada região. Essas linhas de desejo são compiladas, geralmente, tendo como base dados de pesquisas de campo envolvendo entrevistas com moradores. Além disso, tradicionalmente, são usadas categorias para agrupar as diferentes viagens nos chamados "motivos" ou "propósitos". São inúmeros os trabalhos que podem ser usados para exemplificar esse tipo de abordagem e classificação, dentre os quais podese citar Papacostas e Prevedouros (1993, p.310312), Mello (1975, p.51-52 e p.98-103), Hensher e Button (2005) e Stopher e Greaves (2007), com atenção especial para estes últimos, que fornecem extensa revisão sobre os métodos de coleta de dados e apresenta sugestões e desafios para a coleta de dados em transporte.

Stopher e Greaves (2007) apontam que o estado-da-prática pouco evoluiu em 30 anos de pesquisa no que diz respeito a compreensão da "demanda” por transporte, produzindo modelos e resultados mais descritivos, e falhando em gerar conhecimento capaz de explicar os fenômenos de transporte. Apesar de centrar o desenvolvimento de seu trabalho nas questões inerentes ao levantamento de dados para o planejamento de transportes, os autores acabam por abordar aspectos diretamente ligados à compreensão dos fenômenos de transportes em sua intencionalidade. Por exemplo, sobre o estudo dos modelos de demanda eles dizem que

um campo emergente na modelagem de demanda de viagens é o de modelos de processo, ao invés dos modelos de resultado. Modelos de processo são aqueles baseados em processos pelos quais as pessoas tomam decisões, ao invés de se basearem em escolhas observadas, que podem ter ocorrido através de operações sobre uma gama de oportunidades e restrições, bem como um processo comportamental subjascente. (STOPHER; GREAVES, 2007, p.369).

Observe que a preocupação neste ponto não é avaliar a pertinência de um ou outro modelo, mas tão somente fundamentar que a pesquisa e a prática em Transportes têm reconhecido em seu objeto de estudo aspectos que o afirmam como sendo de natureza intencional. Na citação acima, os autores colocam em evidência elementos como o processo de tomada de decisão, e as escolhas das pessoas, pertencentes à dimensão do "Sujeito do Transporte".

Some-se a esse exemplo, a utilização, em pesquisas de transporte, de métodos como preferência declarada como forma de melhor compreender a dinâmica daqueles movimentos.

Sendo assim, observa-se que a interpretação dos fenômenos de transportes enquanto fenômenos humanos, apesar de muitas vezes não estar explícita nos trabalhos científicos, é um pressuposto fundamental para o próprio método sustentado pelas teorias correntes que orientam as pesquisas na área.

Tendo apresentado alguns elementos de suporte para a interpretação intencional, cabe explorar suas implicações inerentes com vistas a orientar um programa geral de pesquisa, bem como sistematizar a produção já existente. 


\subsection{Analisando o fenômeno transporte: um modelo}

Para analisar os fenômenos de transporte, postule-se que existe um processo de transporte e que é composto por alguns momentos distintos, conforme descrito abaixo:

- Momento 01: Uma pessoa (ou grupo de pessoas) precisa desenvolver alguma atividade com vistas a satisfazer alguma necessidade. Ela sabe, ou acredita, com base no senso comum ou outra forma de conhecimento, que a viabilização de sua participação em uma atividade implica uma série de ações concatenadas, dentre as quais inclui aquelas que resultarão no deslocamento de um objeto material específico (objeto tem sentido sintático, ou seja, ele "sofre" a ação);

- Momento 02: Ela procura as formas que dispõe para realização das diversas ações, notadamente aquelas que promoverão esse deslocamento;

- Momento 03: Caso exista alguma forma que atenda às suas expectativas, ela decide por acionar ou não os recursos que dispõe;

- Momento 04: Uma vez acionado, os meios realizam o deslocamento segundo os requisitos postos pela pessoa;

- Momento 05: O deslocamento é finalizado. A pessoa (ou grupo de pessoas) pode desenvolver a atividade que desejava e satisfazer sua expectativa.

Isto posto, o processo de transporte pode ser apresentado conforme figura abaixo:

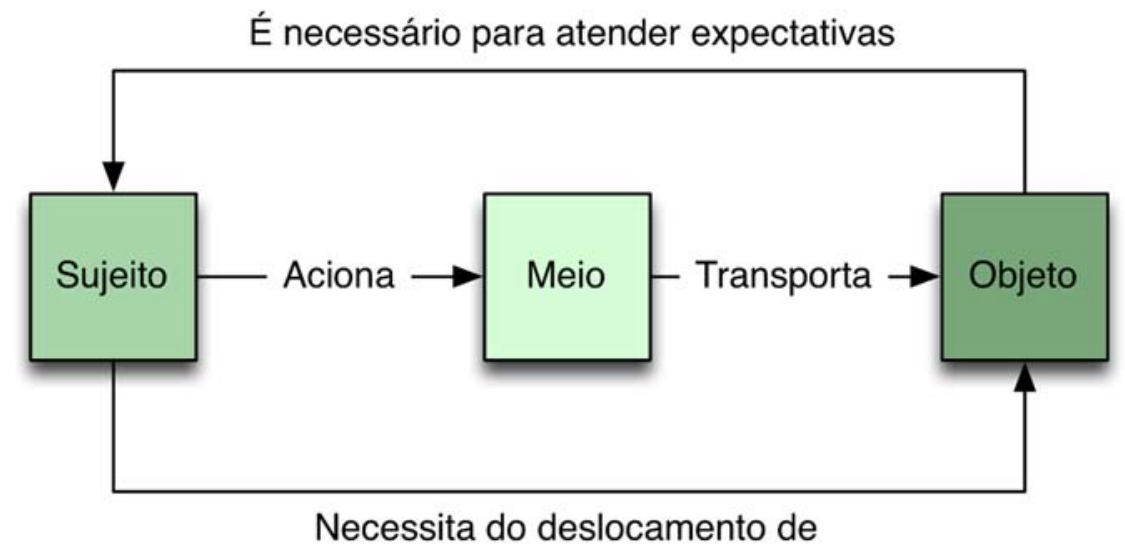

Figura 1 - Elementos determinantes do fenômeno de Transporte. Fonte: Magalhães (2010).

Ou seja, o transporte depende de três elementos para a sua realização: o sujeito do transporte, o meio de transporte e o objeto do transporte. O Sujeito do Transporte é aquele que possui alguma necessidade ou desejo cuja satisfação requer o deslocamento de um objeto qualquer. O Objeto do Transporte, por sua vez, é aquilo cujo deslocamento é necessário para a satisfação das expectativas do Sujeito de Transporte. Para exemplificar, tome-se uma fábrica que deseja produzir seus produtos e para isso precisa que insumos sejam levados até sua unidade produtiva. A fábrica é o Sujeito de Transporte, e o insumo, o objeto.

No que diz respeito a uma ação específica de transportar, a relação entre o Sujeito e o Objeto é mediada por um outro ente, o Meio de Transporte. O Meio de Transporte é aquilo que efetivamente transporta o objeto. Continuando o exemplo anterior, a fábrica pode não ser a responsável pelo deslocamento, podendo contratar, por exemplo, um serviço que se responsabilize por apanhar o produto onde quer que ele esteja, e entregá-lo no local desejado pela fábrica. O Meio de Transporte é, assim, o responsável efetivo pelo fenômeno que observamos de um objeto mudar de um lugar para o outro.

Mas atenção, pois não se deve confundir o meio de transporte do exemplo anterior com, por exemplo, um rio que carrega seixos e outros materiais. Como foi visto anteriormente, entendese que esses dois exemplos tratam de fenômenos bastante distintos: o primeiro, que aqui é chamado de 'transporte' é intencional; o segundo, não (Uma breve explanação sobre a distinção entre fenômenos intencionais e não-intencionais foi oferecida anteriormente, na seção 3.3).

Além disso, o esquema apresentado pode, 
por vezes, conduzir a entendimentos equivocados e deve-se ter atenção. Para ilustrar, cabe citar alguns casos exemplares:

- Situação 01: Uma indústria de automóveis contrata o transporte de seus produtos a uma concessionária situada em outra região geográfica.

- Sujeito do Transporte: a indústria de automóveis;

- Meio de Transporte: o sistema que envolve a infraestrutura de transporte existente (veículos, vias, edificações, equipamentos), o operador do serviço, dentre outros agentes;

- Objeto do Transporte: os automóveis.

- Situação 02: Um estudante desloca-se a pé para a escola.

- Sujeito do Transporte: o estudante;

- Meio de Transporte: o sistema que envolve a infraestrutura de transporte existente (calçadas, calçadões, passarelas e outros espaços do pedestre), e parte do corpo do estudante (seu sistema locomotor);

- Objeto do Transporte: o estudante (especificamente, seu corpo).

A vantagem do modelo ora proposto é que este força o analista a tornar explícitos a tornar explícitos a composição ( $\mathscr{C}$ ) e ambiente ( ש ) do sistema sob foco. Isto auxilia não apenas no processo mecânico de modelagem - que exige, ainda, a indicação da respectiva estrutura $\left(\mathscr{C}^{\circ}\right)$ como também, do ponto de vista teórico, põe em evidência os aspectos que exigem abordagem interdisciplinar e multisetorial

\subsection{Diferenciando o transporte}

Na definição do fenômeno Transporte, em consequência do que foi visto até aqui, faz-se necessário contornar alguns indesejáveis traços de forte fisicalismo (apelo ou crença que a Física, sozinha, seria abrangente o suficiente para explicar os mais diversos fenômenos).

O senso comum, ainda pautado na física clássica, nos diz que deslocamento é qualquer mudança de posição espacial de um objeto ou ponto material no decorrer do tempo. Assim, o deslocamento das águas, a queda de uma maçã, o vôo de uma ave, o fluxo de automóveis e pessoas nas ruas, todos são exemplos de deslocamento. No campo das ciências, a Física (e dentro dela a Cinemática e Mecânica) é a aquela tradicionalmente associada ao estudo desses fenômenos, tendo ela própria definido o termo. Sendo assim, surge a questão: porque defende-se aqui que Transporte, mesmo sendo um tipo de deslocamento, não é capaz de ser suficientemente explicado por apelo a processos e teorias da física (incluindo aquelas derivadas da teoria da gravitação)?

Eis a razão: a Física ensina que os deslocamentos têm uma causa, uma força (física) que determinou seu início. A abordagem dessa ciência se restringe a explicar o relacionamento entre as forças e os deslocamentos. No entanto, não há a preocupação em explicar a finalidade do fenômeno, ou seja, para que ele ocorre, o que seria equivalente a uma explicação teleológica das forças que o determinam (por exemplo, que resposta poderia ser dada para a questão de qual seja a finalidade do movimento dos planetas?). Para a Física, eles não são intencionais, não têm propósito, e esse corte ontológico e epistemológico é que a distingue e a incompatibiliza ao adequado tratamento do fenômeno Transporte.

Agora, retome-se as definições de transporte vistas anteriormente. Transporte seria, então, dentre os deslocamentos, aqueles correspondentes ao de pessoas e mercadorias. Aqui, generalize-se esses dois elementos, pessoas e mercadorias, para objetos materiais, palpáveis “coisas” na acepção dada por Bunge (1977), pois dessa forma os distinguimos de coisas como "informação" e "energia”. Ainda, observando mais atentamente, e recuperando o comentário final da seção anterior, os fenômenos de transporte seriam carregados de intencionalidade, o que significa dizer que acontecem por uma razão, uma vontade ou propósito. Assim sendo, determina-se uma distinção crucial: a intencionalidade.

Então, pode-se definir transporte como deslocamento INTENCIONAL de um objeto material, palpável.

Diante desta definição fica evidente a limitação da abordagem da Física para tratar as questões relacionadas a Transporte: ela desconsidera a intencionalidade enquanto elemento necessário para a explicação dos fenômenos, sendo, portanto, insuficiente para prover teorias e instrumentos para o estudo desta classe especial de fenômenos.

Os fenômenos de transporte são de natureza humana e, portanto, abertos a interpretações de cunho teleológico, para os quais as ciências naturais não possuem arcabouço teórico, metodológico nem instrumental adequados, apesar de 
serem passíveis de intepretação por essas ciências. Essa é uma das implicações cruciais da definição de transporte colocada aqui. Como exemplo da abordagem teleológica para o planejamento de transportes pode-se citar o Sistema de Indicadores finalísticos desenvolvidos para o Ministério dos Transportes para avaliação dos programas nacionais do setor no PPA (BRASIL - MINISTÉRIO DOS TRANSPORTES, 2007).

Então, coloca-se a questão: qual a finalidade do transporte?. E, nisso, Morlock (1978, p.5) e Papacostas e Prevedouros (1993, p.1) já ensaiaram uma resposta, a qual é escrita aqui de forma mais geral: a satisfação de uma expectativa individual ou coletiva.

Ou seja, a finalidade do transporte é a satisfação de uma expectativa individual ou coletiva. E, assim sendo, aí reside seu telos. Isso significa dizer que, para explicar os fenômenos de transporte, deve-se explorar e estudar os condicionantes postos pelo Ambiente ( $\mathscr{E}$ ), partes de outros sistemas e subsistemas sociais.

\subsection{Explorando as relações entre os ele- mentos fundamentais do transporte: a busca de pistas na compreensão do me- canismo}

Como visto anteriormente, a interação entre três elementos é fundamental para a produção do fenômeno de transporte: o Sujeito do Transporte, o Meio do Transporte e o Objeto do Transporte. Para que o fenômeno do transporte possa acontecer, uma relação deve ser estabelecida entre o Sujeito e o Meio e entre o Meio e o Objeto, no sentido do transporte. Como foi visto, a relação no sentido sujeito-meio é ‘aciona' e no sentido meio-objeto é 'transporta'. O resultado da possibilidade de estabelecimento dessas relações determina uma propriedade ao objeto: a mobilidade, a propriedade daquilo que pode ser transportado. A acessibilidade é, por definição, uma propriedade do meio do transporte que pode interagir com o sujeito e com o objeto, no âmbito específico do transporte. Desta forma, a acessibilidade pode ser decomposta em dois componentes: a acessibilidade sujeito-meio e a acessibilidade meio-objeto.

Compreende-se, assim, que estudar o transporte é abordar os elementos aqui colocados, suas propriedades e relações. É, ainda, a construção teórica de sistemas de transporte e a compreensão de seu mecanismo. O objeto de estudo de Transportes são os Sistemas de Transporte. Dito isso, é possível formalizar algumas ideias aqui apresentadas dentro da notação utilizada por Bunge.

(i) o trabalho da pesquisa em transporte é produzir modelos de sistema de transporte, cuja forma mínima é:

$$
\sigma_{t}=\left\langle\mathscr{C}_{t}, \mathscr{E}_{t}, \mathscr{\vartheta}_{t}\right\rangle
$$

onde:

$$
\begin{aligned}
& \sigma_{t} \text { : sistema de transporte } \\
& \mathscr{C}^{\circ} \text { : composição do sistema de transporte } \\
& \mathscr{E}_{\iota} \text { : ambiente do sistema de transporte } \\
& \mathscr{\ell}_{\circ} \text { : estrutura do sistema de transporte }
\end{aligned}
$$

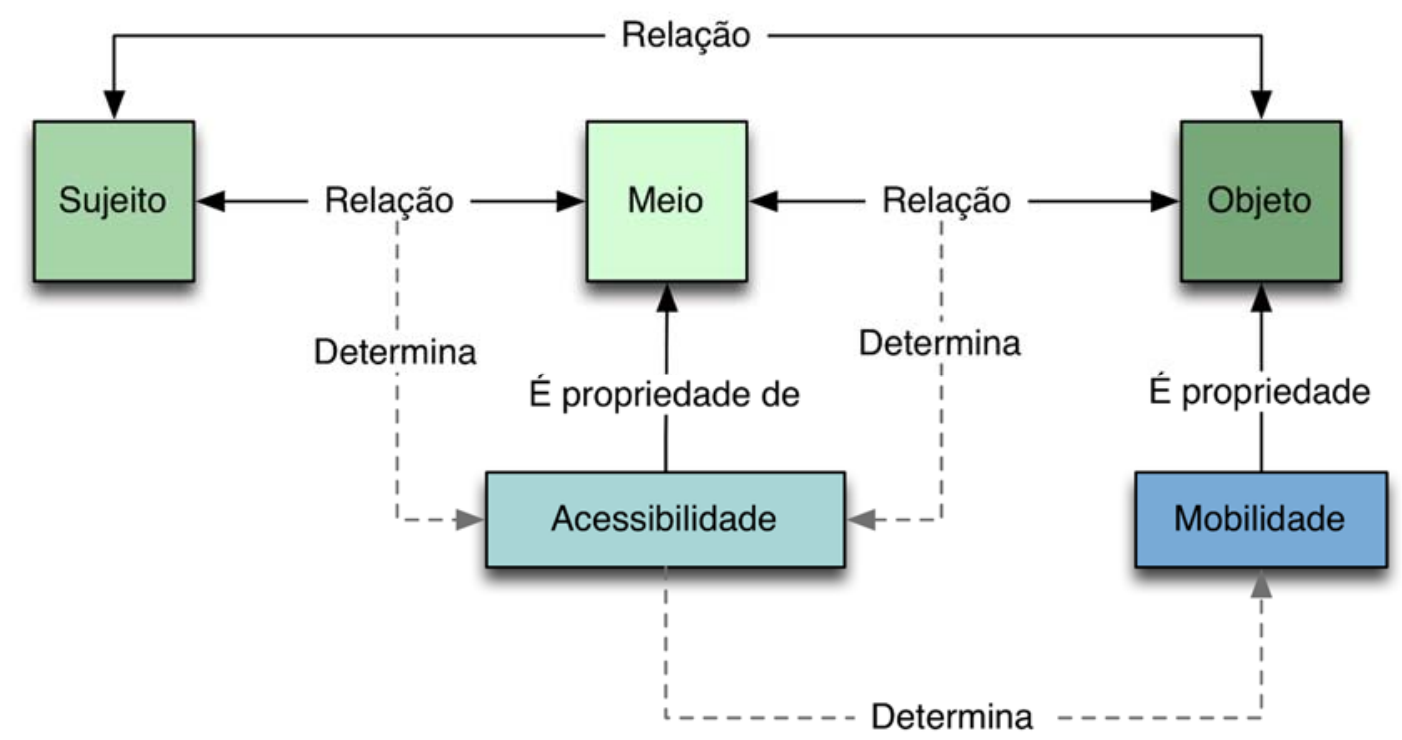

Figura 2 - Relações entre os elementos fundamentais do Transporte e as propriedades fundamentais do Meio e do Objeto de Transporte. Fonte: Magalhães (2010). 
A pesquisa em Transporte deve utilizar, nesse contexto teórico, recursos metodológicos e instrumentais para a análise de sistemas complexos. Seu trabalho é conjecturar componentes, ambiente e estrutura do sistema de transporte, partindo de proposições mais simples, e trabalhando em incrementos teóricos. Para o cumprimento dessa tarefa, são instrumentais as ideias de A-Composição, A-Ambiente e A-Estrutura), que possibilitam estabelecer um nível de complexidade a partir do qual a análise deve ser feita. Isso evita que o analista se perca nos diferentes níveis de complexidade a partir dos quais a análise pode partir, que é uma das grandes armadilhas do holismo.

Como recurso inicial de análise, cabe entender um sistema de transporte como tecnossistema - subsistemas sociais nos quais os artefatos e a tecnologia têm especial atenção, ou relevância - cujos inputs são pessoas e coisas a transportar, energia, artefatos, além de ações oriundas dos sistemas econômico, político, cul- tural e familiar. Os outputs são coisas transportadas e lixo (coisas residuais não propositalmente produzidas pelas atividades do sistema). Assim, na análise dos sistemas de transporte deve-se sempre partir desses elementos como linha condutora para a enumeração dos componentes, ambiente e estrutura, conforme abaixo ilustrado. A Figura 3 apresenta o modelo "Caixa-Preta”, um dos recursos mais rudimentares para o início da análise de um sistema. Esse tipo de modelo busca por em evidência as relações entre a Composição do sistema e seu Ambiente. À esquerda representam-se os inputs; à esquerda, os outputs; e, ao topo, ações oriundas de outros sistemas mais amplos. Este é O PRIMEIRO PASSO para a análise dos sistemas de transporte à luz da teoria sistemista de Bunge sendo o passo seguinte, não desenvolvido aqui pela limitação de espaço, seria a análise da AComposição, A-Ambiente e A-Estrutura, partindo das relações explicitadas na Figura 3.

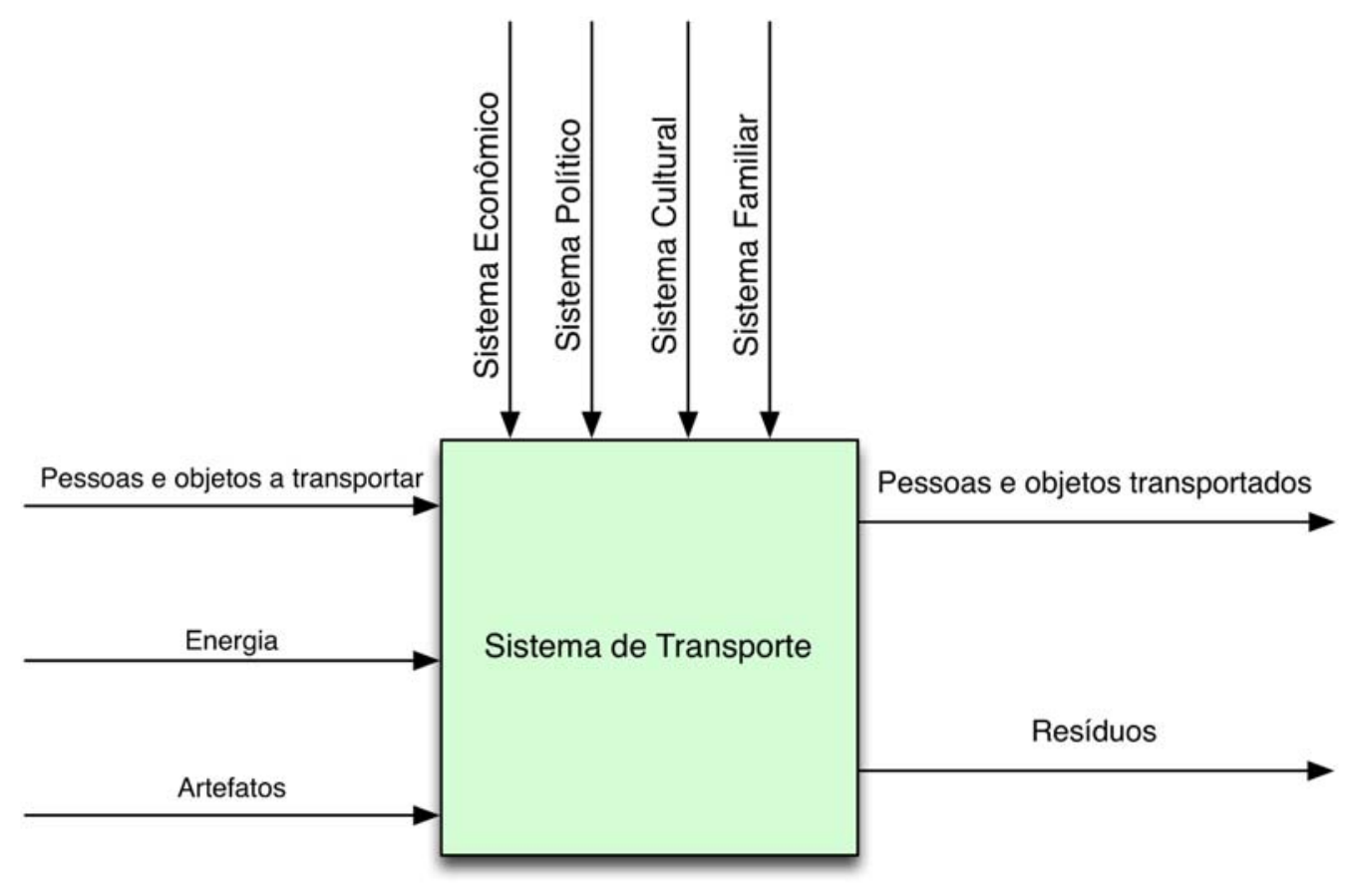

Figura 3 - Modelo "Caixa-Preta" do Sistema de Transporte. Fonte: Magalhães (2010).

\section{COMENTÁRIOS FINAIS}

Como pôde ser visto ao longo do trabalho, a natureza dos fenômenos de transporte é essencialmente humana, social. Essa mudança de enfoque e compreensão requer adequado desenvolvimento e revisão das teorias e instrumentos correntes para abordagem dos problemas de transporte, principalmente no que diz respeito ao planejamento.
No âmbito filosófico-teórico mais geral, a teoria de Bunge se mostra bastante fecunda para o desenvolvimento e formalização de uma teoria

dos sistemas de transportes, também sendo uma ferramenta analítica bastante poderosa.

No âmbito da previsão, teorias como a dos modelos gravitacionais, oriundos da física clás- 
sica e que possuem postulados ontológicos específicos, perdem sua coerência teórica com o fenômeno, tornando-se, por si, incoerentes e inconsistentes com a natureza do fenômeno que tentam explicar. Correspondências tornam-se meras coincidências, pois não há uma teoria explicativa robusta para sustentar. Mas, se assim for, como contornar essas questões e que ferramentas podem ser utilizadas?

Atualmente, no campo da ciência da computação e de teoria de sistemas, vêm se popularizando novas teorias e ferramentas que podem ser bastante fecundas para tratar o tema, a exemplo de inteligência artificial e sistemas multiagentes. No campo da Economia, a teoria dos jogos também se apresenta como um arcabouço teórico e instrumental bastante fecundo. A psicologia, por tratar de comportamentos humanos, pode oferecer também elementos teóricos e instrumentais significativos.

O consistente desenvolvimento dessas novas ferramentas, como também da base filosófico-teórica subjacente, requer enorme esforço de pesquisa, cujo efetivo resultado pode ainda demorar algum tempo. Tudo dependerá do esforço de pesquisa dedicado ao tema, e do efetivo envolvimento da comunidade científica no processo. No entanto, acredita-se que serão resultados bastante coerentes e mais condizentes com os fenômenos reais, culminando em um planejamento mais efetivo, eficaz e eficiente.

\section{REFERÊNCIAS}

ANDLER, Daniel; FAGOT-LARGEAULT, Anne; SAINT-SERNIN, Bertrand. (2005) Filosofia da Ciência. Volume II. Rio de Janeiro: Atlântica.
BRASIL - MINISTÉRIO DOS TRANSPORTES (2007). Metodologia Integrada de Suporte ao Planejamento, Acompanhamento e Gestão dos Programas Nacionais de Transporte (Projeto Indicadores) - Relatório Síntese. Brasília: Ministério dos Transportes/SEGES - Universidade de Brasília/CEFTRU.

BUNGE, Mario A. (1977) Treatise on Basic Philosophy - Ontology I: The Furniture of the World. Dordrecht: D. Reidel Publishing Company.

BUNGE, Mario A. (1979) Treatise on Basic Philosophy - Ontology II: A World of Systems. Dordrecht: D. Reidel Publishing Company.

HAY, William W (1977). An Introduction to Transportation Engineering. 2.ed. New York: John Wiley\&Sons.

HENSHER, David; BUTTON, Kenneth. (2005) Handbook of Transport Modelling. Oxford: Elsevier.

HOUAISS, A; VILLAR, M. de S.; FRANCO, F. M. de. (2001) Dicionário Houaiss da Língua Portuguesa. Rio de Janeiro: Objetiva.

MAGALHÃES, Marcos T. Q. (2010). Fundamentos para a Pesquisa em Transportes: Reflexões Filosóficas e Contribuição da Ontologia de Bunge. Tese de Doutorado em Transportes. Brasília: Universidade de Brasília.

MAGALHÃES, M. T. Q., SILVEIRA, L. S., GALINDO, E. P., GOMES, H. A. S., VILLELA, T. M., YAMASHITA, Y., ARAGÃO, J. J. G. (2007). Teleological Framework for Transport Planning and Evaluation: A Tool in the Search for Integrated and Meaningful Solutions for Better Results. Proceedings of the Thredbo 10 - International Conference on Competition and Ownership of Land Passenger Transport.

MELLO, José C. (1975) Planejamento dos Transportes. São Paulo: McGraw-Hill do Brasil.

MORLOCK, Edward K. (1978) Introduction to Transportation Engineering and Planning. Tóquio:McGraw-Hill.

MUMFORD, Lewis. (1998) A Cidade na História: suas origens, transformações e perspectivas. Tradução Neil R. da Silva. São Paulo: Martins Fontes.

PAPACOSTAS, C. S.;PREVEDOUROS, P. D. (1993) Transportation Engineering and Planning. Englewood Cliffs: Prentice Hall.

STOPHER, Peter R.; GREAVES, Stephen P. (2007) Household Travel Surveys: Where are we going? In: Transportation Research Part A: Policy and Practice. Volume 41, Issue 5, p.361-381, Science Direct. doi:10.1016/j.tra.2006.09.005

SUSSMAN, Joseph (2000). Introduction to Transportation Systems. Norwood: Artech House. 